\title{
Geographical and Functional-Morphological Variations of the Skull in the Gray- Bellied Squirrel
}

\author{
Hideki ENDO ${ }^{1)}$, Junpei KIMURA ${ }^{2)}$, Tatsuo OSHIDA ${ }^{3)}$, Brian J. STAFFORD ${ }^{4,5)}$, Worawut RERKAMNUAYCHOKE ${ }^{6}$, \\ Takao NISHIDA $^{6}$, Motoki SASAKI ${ }^{7)}$, Akiko HAYASHIDA ${ }^{7)}$ and Yoshihiro HAYASHI ${ }^{8}$ \\ ${ }^{1)}$ Department of Zoology, National Science Museum, Tokyo, 3-23-1 Hyakunin-cho, Shinjuku-ku, Tokyo 169-0073, ${ }^{2)}$ Department of \\ Veterinary Anatomy, College of Bioresource Sciences, Nihon University, Fujisawa, Kanagawa 252-8610 Japan, ${ }^{3)}$ Laboratory of Molecular \\ Ecology, Department of Biology, Tunghai University, Taichung, Taiwan, R.O.C,, ${ }^{4}$ Mammal Division, National Museum of Natural History, \\ Smithsonian Institution, Washington DC, ${ }^{5)}$ Department of Anatomy, Howard University College of Medicine, Washington DC, U.S.A., \\ ${ }^{6}$ Department of Veterinary Anatomy, Faculty of Veterinary Medicine, Kasetsart University, Bangkok, Thailand, ${ }^{7)}$ Department of \\ Veterinary Anatomy, Obihiro University of Agriculture and Veterinary Medicine, Obihiro, Hokkaido 080-8555 and ${ }^{81}$ Department of \\ Global Agricultural Sciences, Graduate School of Agricultural and Life Sciences, The University of Tokyo, Tokyo 113-8657, Japan
}

(Received 5 April 2003/Accepted 17 November 2003)

\begin{abstract}
The geographical variations of the skulls were osteometrically examined in the gray-bellied squirrel (Callosciurus caniceps) from the populations of Korat, Ranong, southernmost Thailand, and Terutau Island. The skull size was larger in northern population than in the southern population in the continental mainland. The zoogeographical influences of the Isthmus of Kra remained unclear, since the plots from Korat population were intermingled with those from southernmost Thailand population in the principal component charts. Although Korat population has been thought to belong to north group, we suggest that Ranong and southernmost Thailand populations may contain individuals from both north and south groups separated by the ancient Kra barrier. Terutau Island population was similar to southernmost Thailand population in skull size, although Terutau population has been isolated in the island and separ ated from the south group of the Isthmus of Kra. In the proportional analysis the interorbital space was narrower and the binocular sense has been well-developed in Terutau population. It suggests that this population has been highly adapted to arboreal behavior. In contrast, the skull with larger interorbital space was more adaptive for terrestrial life in Korat population. The canonical discriminant analysis could clearly separate the four populations in the scattergrams of discriminant scores.

KEY WORDS: Callosciurus caniceps, geographical variation, gray-bellied squirrel, osteometry, skull.
\end{abstract}

J. Vet. Med. Sci. 66(3): 277-282, 2004

The Indomalayan Region includes about 10 species of the genus Callosciurus $[2,3,13]$. Among them the gray-bellied squirrel (Callosciurus caniceps) represents one of the most typical arbo-terrestrial squirrels in this region. The species is widely distributed in the north and central Thailand and the Malayan Peninsula, and shows complicated skin color variations in each locality [1,8-12]. However, the osteometrical data have not been reported from the large distribution areas and the geographical variations have remained unclear in skull shape. We have expected that the skull shape has been functionally adapted to various natural environments within the species. In this study, therefore, the osteometrical and related statistical analysis were carried out in the skull to clarify the geographical variation among populations and to confirm the functional adaptation in each locality.

\section{MATERIALS AND METHODS}

We examined 74 skulls of the gray-bellied squirrel that have been stored in the Mammal Division in National Museum of Natural History of Smithsonian Institution. Museum numbers of each specimen are provided in Appendix 1 . The skull specimens with fully erupted molars were used and considered as adult. Sex determination was dependent on the description of biological data of specimens. The composition of origin and their abbreviations, and sex are shown in Table 1. We selected only four geographical populations (Table 1) from all subspecies of the gray-bellied squirrel, since relatively numerous specimens have been obtained from these four localities and stored as Museum Collection. Korat population was identified as Callosciurus caniceps caniceps, Ranong population as Callosciurus caniceps bimaculatus, Terutau Island population as Callosciurus caniceps lacevensis or Callosciurus caniceps adangensis in the biological record of the Museum specimens. Since the skin color variations from southernmost Thailand population are complicated, we considered them as one group in the osteometrical study. Skull measurement data were obtained with vernier calipers to the nearest 0.05 $\mathrm{mm}$. Measurements are defined in Table 2, and were based on Driesch [4]. Differences of mean values among localities were examined by Student's $t$-test. We calculated the proportion indices as quotients of each measurement value divided by geometric mean of all measurement values. The significant differences of proportion indices were evaluated among populations by nonparametric U-test using software Statistica (Statsoft Inc., Tokyo, Japan). Principal component analysis and canonical discriminant analysis were carried out with all measurement data to clarify the geographical variation among localities by the use of the same software. 
Table 1. Locality and sex composition of the specimens

\begin{tabular}{lccc}
\hline Origin of Specimens & Symbols & Male & Female \\
\hline Korat & $\mathrm{K}$ & 4 & 2 \\
Ranong & $\mathrm{R}$ & 10 & 5 \\
Southernmost Thailand & $\mathrm{S}$ & 21 & 24 \\
$\quad$ (Trang, Nakhon Si Thammarat, Surat Thani, Songkla, Hat Yai) & $\mathrm{T}$ & 6 & 2 \\
Terutau Island & & 41 & 33 \\
\hline
\end{tabular}

Table 2. List of skull and mandibular measurements and their abbreviations

\begin{tabular}{ll}
\hline Cranium & \\
Profile length & PL \\
Maximum length & ML \\
Condylobasal length & CL \\
Short lateral facial length & SL \\
Maximum width of the nasal bone & MWN \\
Least breadth between the orbits & LBO \\
Least breadth of caudal point of zygomatic process of frontal bone & LBC \\
Greatest neurocranium breadth & GNB \\
Greatest occipital breadth & GOB \\
Median palatal length & MPL \\
Dental length & DL \\
Length of molar row & LMR1 \\
Greatest palatal breadth & GPB \\
Length from Basion to Staphylion & LBS \\
Length from Basion to the most rostral point of zygomatic arch & LBR \\
Length from Basion to the most medial point of orbit & LBM \\
Length from Basion to the saggital and rostral point of temporal bone & LBSR \\
Height from Akrokranion to Basion & HAB \\
Mandible & \\
Length from the condyle & \\
Length of molar row & LC \\
Thickness of mandible at middle point of M1 & LMR2 \\
Height of the mandible at M1 & TM \\
Aboral height of the vertical ramus & HM \\
Oral height of the vertical ramus & AHR \\
\hline
\end{tabular}

The measurement items were based on Driesch [4].

\section{RESULTS}

Mean values and standard errors of the 24 measurements are given in Table 3. Statistical differences in these measurements between all combinations of populations are shown in Table 4. We used the limit of $5 \%$ to evaluate the statistical differences. The statistical differences of mean values were obviously confirmed among the four populations. The skull size was larger in northern population than in the southern population among $\mathrm{K}, \mathrm{R}$, and $\mathrm{S}$ materials in mean values. The mean values of $T$ population were obviously smaller than those of $\mathrm{K}$ population. The results of $t$ test showed significant size differences between many combination of localities, although the relationships between S$\mathrm{T}$ in both sexes and $\mathrm{K}-\mathrm{R}$ in female did not significantly indicate the differences in many measurements (Table 4). In the comparison between $\mathrm{S}$ and $\mathrm{T}$ populations, SL, DL, LMR1 and GPB were not different. It indicated that the size of the spranchnocranium region was similar between the two pop- ulations. The measurement values were also similar in mandibular size in these two populations.

The proportion indices are arranged in Table 5, and their significant differences confirmed by nonparametric U-test among localities are shown in Table 6. The significant differences were not observed in many indices in female. However, CL and LBS were larger and LBC smaller in T population than in the other populations. SL and LBO were larger and GNB and GOB smaller in K population. The tendency was statistically obvious in male, and the results of female in some locality combinations were consistent with those of male.

The principal component charts are shown in Fig. 1. The loading factors are arranged in each measurement (Table 7). The plots of the species were considered as four groups of $\mathrm{K}, \mathrm{R}, \mathrm{S}$ and $\mathrm{T}$ in charts of both sexes. However, the plot distribution of $\mathrm{R}$ was intermingled with $\mathrm{S}$ in both sexes, $\mathrm{T}$ with $\mathrm{S}$ in female. $\mathrm{K}$ plots in both sexes and $\mathrm{T}$ plots in male were completely separated from those of the other popula- 
Table 3. Mean values ( $\mathrm{mm})$ and standard deviations for craniometric measurement in various populations

\begin{tabular}{|c|c|c|c|c|c|c|c|c|c|c|c|c|c|c|c|c|c|c|c|c|c|c|c|c|}
\hline & PL & ML & CL & SL & MWN & LBO & LBC & GNB & GOB & MPL & DL & LMR1 & GPB & LBS & LBR & LBM & LBSR & HAB & LC & LMR2 & $\mathrm{TM}$ & HM & AHR & OHR \\
\hline \multicolumn{25}{|l|}{ Korat } \\
\hline \multirow[t]{2}{*}{ Male } & 56.83 & 6.53 & 50.43 & 4.20 & 7.86 & 20.95 & 19.58 & 21.91 & 23.78 & 29.03 & 28.08 & 10.96 & 13.29 & 21.55 & 41.84 & 33.90 & 25.73 & 14.70 & 37.41 & 11.36 & 4.06 & 9.19 & 19.50 & 18.69 \\
\hline & & & 0.6 & & 23 & 0.75 & & 0.97 & & & & & & & & & & 0.43 & & & 0.18 & .52 & .69 & 0.69 \\
\hline \multirow[t]{2}{*}{ Female } & 55.65 & .55 & 49.28 & 3.60 & 7.65 & 20.25 & 19.28 & 22.00 & 23.73 & 28.43 & 26.93 & 11.48 & 13.20 & 1.20 & 40.48 & 33.25 & 24.58 & 14.03 & 35.50 & 11.23 & 4.08 & 93 & 19.08 & 17.83 \\
\hline & 0.78 & & 0.81 & .28 & .07 & 0.21 & 0.60 & 0.28 & 0.46 & & 0.32 & & & & 0.60 & 0.07 & & 0.11 & 0.71 & 0.32 & 0.11 & 0.18 & 0.04 & 0.60 \\
\hline \multicolumn{25}{|l|}{ Ranong } \\
\hline \multirow[t]{2}{*}{ Male } & 5 & & 7.76 & 2.62 & 70 & 18.96 & 19.19 & 22.31 & 23.41 & 7.38 & 6.21 & & 12. & 0.68 & 40.34 & 86 & & 13.96 & & 10.96 & 4.05 & 46 & 8.32 & 17.39 \\
\hline & 1.4 & & 1.33 & 0.74 & 0.46 & 1.11 & 0.76 & 0.85 & 0.90 & 0.77 & 0.85 & 0.27 & 0. & 0.73 & 1.38 & 3 & & 0.43 & & 0.28 & 0.33 & 30 & 0.52 & 0.49 \\
\hline \multirow[t]{2}{*}{ Female } & 53.56 & 53.37 & 47.48 & 22.31 & & 19.42 & 18.98 & 22.11 & 22.90 & 27.26 & 26.12 & & & & 40. & & & 13.83 & 35.19 & 12 & 82 & 44 & 18.40 & 17.59 \\
\hline & 0.43 & & & 0 & & & & & & & & & & & & & & & & & 0.25 & 12 & 11 & 0.99 \\
\hline \multicolumn{25}{|c|}{ Southemmost Thailand } \\
\hline \multirow[t]{2}{*}{ Male } & 51.01 & 50.95 & 4.98 & 20.81 & & 17.75 & 18.05 & 21.29 & 22.06 & 25.64 & 24.52 & 10.25 & 12.10 & 19.67 & 37.59 & & & 13.50 & 32.90 & 10.34 & 3.67 & 7.83 & 17.43 & 16.59 \\
\hline & & & & & & & & & & & & & & & & & & & & & & 51 & & 0.91 \\
\hline \multirow[t]{2}{*}{ Female } & 50.38 & 50.26 & 44.33 & 20.38 & & 17.40 & 18.28 & 21.13 & 21.56 & 25.30 & 24.26 & 10.41 & 12. & 19.22 & 37.25 & 30.64 & 23.45 & 13.32 & 32.38 & 10.48 & 3.76 & .83 & 17.05 & 16.22 \\
\hline & 2.01 & 1.97 & 1.99 & 1.22 & 0.36 & 1.11 & 0.69 & & 0.91 & 1.04 & 0.94 & & & & 1.56 & 1.25 & 0.87 & 0.56 & 1.56 & 0.40 & 0.19 & 0.44 & 0.89 & 0.94 \\
\hline \multicolumn{25}{|c|}{ Terutau Id. } \\
\hline \multirow[t]{2}{*}{ Male } & 52.5 & & 4 & & & 17.7 & 17.1 & 20.05 & 22.38 & 26.47 & & & & & & & & & & & 3.7 & & 22 & 16.93 \\
\hline & & & & & & & & & & & & & & & & & & & & & 23 & 24 & & 0.20 \\
\hline \multirow[t]{2}{*}{ Female } & 50.73 & 50.20 & 45.43 & 20.58 & 7.05 & 17.23 & 16.90 & 19.85 & 21.23 & 25.25 & 23.98 & 10.00 & 12.05 & 20.30 & 37.98 & 30.55 & 22.33 & 12.53 & 33.30 & 10.15 & 3.55 & 7.85 & 17.78 & 16.75 \\
\hline & 1.17 & 0.92 & 0.74 & 0.60 & 0.49 & 1.45 & 0.28 & 0.42 & 0.32 & 0.42 & 0.46 & 0.07 & 0.35 & 0.21 & 0.74 & 0.28 & 0.04 & 0.18 & 0.21 & 0.14 & 0.07 & 0.21 & 0.46 & 0.14 \\
\hline
\end{tabular}

Mean values are arranged in upper row, standard deviations in lower row.

Table 4. Significant differences of measurements among various populations

\begin{tabular}{|c|c|c|c|c|c|c|c|c|c|c|c|c|c|c|c|c|c|c|c|c|c|c|c|c|}
\hline & PL & ML & CL & SL & MWN & LBO & LBC & GNB & GOB & MPL & DL & LMR1 & GPB & LBS & LBR & LBM & LBSR & HAB & LC & LMR2 & $\mathrm{TM}$ & HM & AHR & OHR \\
\hline \multicolumn{25}{|l|}{ Male } \\
\hline KX & & & & 0.001 & & & & & & & & & & & & & & 0.006 & & & 0.473 & 0.003 & 0.002 & 0.001 \\
\hline & & & & & & & & & & & & & & & & & & & & & & & & \\
\hline & & 000 & 00 & 00 & & & & & & & & & & & & & & & & & & & & \\
\hline & 000 & 000 & 000 & 000 & 001 & & & & & & & & & & & & & & & & & & & 007 \\
\hline & & & & & & & & & & & & & & & & & & & & & & & & \\
\hline & & 065 & 005 & 055 & & 487 & 0.00 & 0 & & 0.04 & 0.13 & 9 & & 0.00 & 0.0 & 0.2 & $t$ & 2 & 0.007 & 4 & 0.2 & & & 0.186 \\
\hline \\
\hline & & & 022 & 001 & & & & & & & & & & & & & & & & & & & & 0.387 \\
\hline & & & & & & & & & & & & & & & & & & & & & & & & \\
\hline & & & 019 & 012 & & & & & & & & & & & & & & & & & & & & .066 \\
\hline $\mathrm{R}$ & 0.001 & 001 & 0.001 & 001 & 043 & 0.000 & 0.020 & 012 & 0.002 & 0.000 & 0.000 & 0.008 & 0.000 & 0.013 & 0.000 & 0.000 & & 30 & 0.000 & & 0.268 & 03 & .003 & .003 \\
\hline RXT & 002 & 001 & 0.013 & .001 & & 0.021 & 0.001 & .001 & 0.007 & 0.002 & & & & & & & & & & & & & 28 & 0.155 \\
\hline SXT & 0.406 & 0.483 & 0.226 & 0.415 & 0.500 & 0.419 & 0.005 & 0.029 & 0.305 & 0.474 & 0.336 & 0.092 & 0.269 & 0.091 & 0.264 & 0.462 & 0.044 & 0.030 & 0.209 & 0.133 & 0.073 & 0.472 & 0.138 & 0.218 \\
\hline
\end{tabular}

Each value indicates the limit percentage in which the significant differences are confirmed between the two populations.

Table 5. The proportion indices in each measurement of various populations

\begin{tabular}{|c|c|c|c|c|c|c|c|c|c|c|c|c|c|}
\hline & & PL & ML & CL & SL & MWN & LBO & LBC & GNB & GOB & MPL & DL & LMR 1 \\
\hline \multirow[t]{4}{*}{ Male } & Korat & 2.711 & 2.696 & 2.405 & 1.154 & 0.375 & 0.999 & 0.934 & 1.045 & 1.134 & 1.385 & 1.339 & 0.523 \\
\hline & Ranong & 2.702 & 2.692 & 2.378 & 1.126 & 0.383 & 0.943 & 0.956 & 1.111 & 1.166 & 1.363 & 1.305 & 0.539 \\
\hline & Southernmost Thailand & 2.705 & 2.702 & 2.385 & 1.103 & 0.370 & 0.941 & 0.957 & 1.130 & 1.170 & 1.360 & 1.300 & 0.544 \\
\hline & Terutau Id. & 2.732 & 2.720 & 2.455 & 1.121 & 0.386 & 0.922 & 0.893 & 1.043 & 1.164 & 1.377 & 1.298 & 0.543 \\
\hline \multirow[t]{5}{*}{ Female } & Korat & 2.711 & 2.706 & 2.400 & 1.150 & 0.373 & 0.986 & 0.939 & 1.072 & 1.156 & 1.385 & 1.312 & 0.559 \\
\hline & Ranong & 2.683 & 2.673 & 2.378 & 1.117 & 0.369 & 0.972 & 0.951 & 1.107 & 1.147 & 1.365 & 1.308 & 0.546 \\
\hline & Southermost Thailand & 2.691 & 2.685 & 2.368 & 1.088 & 0.377 & 0.929 & 0.977 & 1.129 & 1.152 & 1.352 & 1.297 & 0.557 \\
\hline & Terutau Id. & 2.734 & 2.706 & 2.449 & 1.109 & 0.380 & 0.928 & 0.911 & 1.070 & 1.144 & 1.361 & 1.292 & 0.539 \\
\hline & & GPB & LBS & LBR & LBM & LBSR & HAB & $\mathrm{LC}$ & LMR2 & $\mathrm{TM}$ & HM & AHR & OHR \\
\hline \multirow[t]{4}{*}{ Male } & Korat & 0.634 & 1.028 & 1.996 & 1.617 & 1.227 & 0.701 & 1.785 & 0.542 & 0.194 & 0.438 & 0.930 & 0.891 \\
\hline & Ranong & 0.637 & 1.030 & 2.009 & 1.636 & 1.255 & 0.695 & 1.760 & 0.546 & 0.202 & 0.421 & 0.912 & 0.866 \\
\hline & Southernmost Thailand & 0.642 & 1.043 & 1.993 & 1.660 & 1.252 & 0.716 & 1.744 & 0.548 & 0.195 & 0.415 & 0.924 & 0.879 \\
\hline & Terutau Id. & 0.618 & 1.085 & 2.021 & 1.655 & 1.245 & 0.690 & 1.797 & 0.542 & 0.197 & 0.424 & 0.948 & 0.881 \\
\hline \multirow[t]{4}{*}{ Female } & Korat & 0.643 & 1.032 & 1.972 & 1.620 & 1.197 & 0.683 & 1.729 & 0.547 & 0.198 & 0.435 & 0.929 & 0.868 \\
\hline & Ranong & 0.668 & 1.022 & 2.007 & 1.654 & 1.236 & 0.693 & 1.762 & 0.557 & 0.191 & 0.423 & 0.921 & 0.880 \\
\hline & Southernmost Thailand & 0.652 & 1.027 & 1.990 & 1.637 & 1.253 & 0.712 & 1.730 & 0.561 & 0.201 & 0.418 & 0.911 & 0.866 \\
\hline & Terutau Id. & 0.649 & 1.094 & 2.047 & 1.647 & 1.204 & 0.675 & 1.795 & 0.547 & 0.191 & 0.423 & 0.958 & 0.903 \\
\hline
\end{tabular}

tions. The scattergrams from the canonical discriminant analysis are shown in Fig. 2, and the coefficients of the discriminant function are arranged in Table 8 . The four popu- lations were obviously distinguished in the plots of the discriminant scores unlike the principal component charts from the same osteometrical data. 
Table 6. Significant differences of proportion indices among various populations

\begin{tabular}{|c|c|c|c|c|c|c|c|c|c|c|c|c|c|c|c|c|c|c|c|c|c|c|c|c|}
\hline & PL & ML & CL & SL & MWN & LBO & LBC & GNB & GOB & MPL & DL & LMR1 & GPB & LBS & LBR & LBM & LBSR & HAB & LC & LMR2 & $\mathrm{TM}$ & HM & AHR & DHR \\
\hline \multicolumn{25}{|l|}{ Male } \\
\hline KXR & & & & 0.024 & & 0.034 & 0.258 & 0.034 & 0.024 & 0.203 & & & & 0.777 & 0.671 & 0.396 & 0.066 & 0.396 & 0.258 & 0.671 & 0.480 & 0.157 & 0.258 & 0.090 \\
\hline $\mathrm{KX}$ & & & & & & & & & & & & & & & & & & & & & & & & \\
\hline KX & & 136 & 033 & 055 & 088 & 011 & 111 & 831 & 088 & 831 & 033 & 201 & 088 & 011 & 286 & & & & 770 & & 0.670 & & & 670 \\
\hline $\mathrm{RX}$ & & 526 & 291 & 009 & 0.205 & .866 & 0.499 & & 0.767 & 0.704 & & & & & & & & & & & & & & 139 \\
\hline & & & & & & & & & & & & & & & & & & & & & & & & 51 \\
\hline SXT & 0 & 199 & 0.002 & 0.162 & 0.129 & 0.221 & 0.000 & 0.000 & 0.771 & 0.199 & 0.953 & 1.000 & 0.012 & 0.003 & 0.036 & 0.953 & 0.484 & 0.006 & 0.005 & 0.683 & 0.560 & 0.115 & 0.009 & 1.000 \\
\hline \multicolumn{25}{|l|}{ Female } \\
\hline & 0. & 245 & 439 & 053 & & .245 & 1.000 & & 0.699 & 0.699 & 0.699 & & & & & & & & & & & & & 0.699 \\
\hline & & & & & & & & & & & & & & & & & & & & & & & & \\
\hline K & & & & 21 & & & & & & & & & & & & & & & & & & & & .121 \\
\hline RXS & 603 & 0.419 & 0.488 & 083 & 0.326 & 0.011 & 0.119 & 0.073 & 0.644 & 0.299 & 0.166 & 0.356 & 0.119 & 0.729 & 0.166 & 0.225 & 994 & 0.050 & 0.083 & 0.954 & 0.050 & 419 & .525 & .386 \\
\hline RXT & 121 & 0.439 & 0.053 & 0.699 & 0.699 & 0.439 & 0.245 & 0.121 & 0.699 & 0.439 & 0.121 & 0.439 & 0.053 & 0.053 & 0.053 & & & & 0.245 & & 0.439 & 699 & .245 & 0.245 \\
\hline SXT & 0.124 & 0.441 & 0.034 & 0.336 & 0.773 & 1.000 & 0.027 & 0.034 & 0.441 & 0.564 & 0.923 & 0.290 & 0.847 & 0.021 & 0.043 & 0.564 & 0.054 & 0.054 & 0.043 & 0.386 & 0.149 & 0.501 & 0.068 & 0.043 \\
\hline
\end{tabular}

Each value indicates the limit percentage in which the significant differences are confirmed between the two populations.
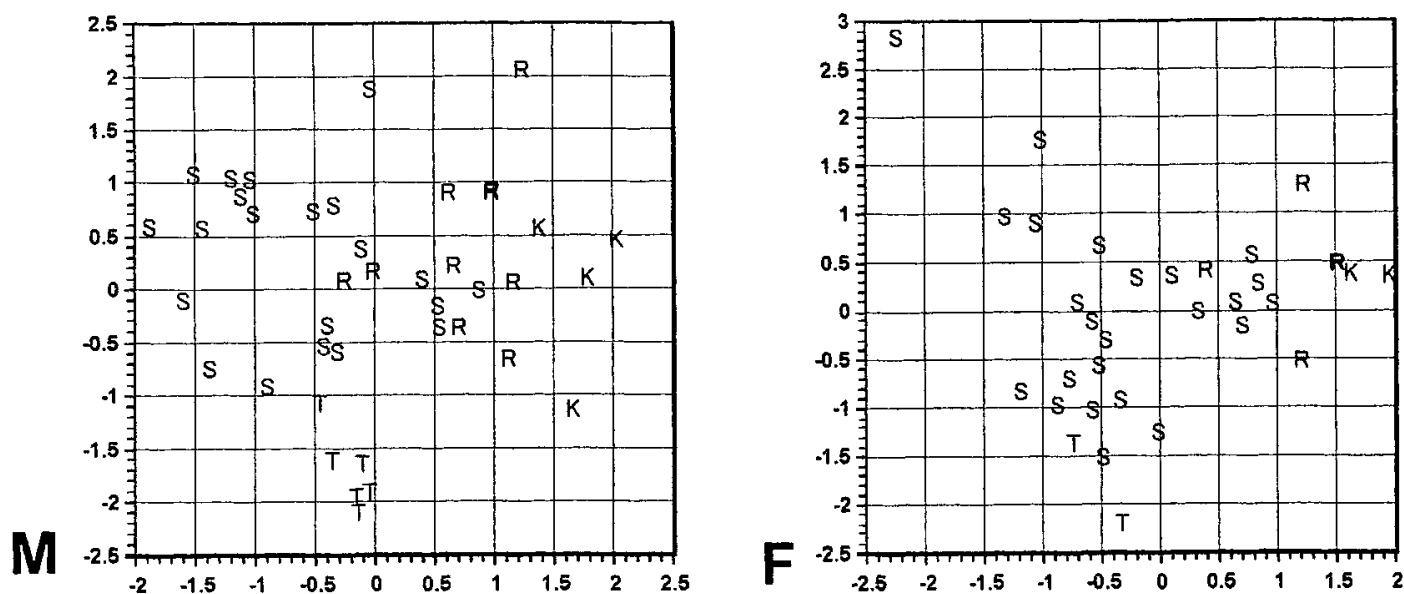

Fig. 1. The principal component chart of skulls of the gray-bellied squirrel between the first and second transformed variables from 24 measurements. M) Male, F) Female. The symbols plotted in the chart are shown in Table 1. Horizontal axis, the first principal component. Vertical axis, the second principal component.

\section{DISCUSSION}

Since the important measurements as PL, ML and CL showed statistical difference between $\mathrm{K}, \mathrm{R}, \mathrm{S}$ populations (Tables 3 and 4), the traditional Bergmann's rule may be established among the three mainland populations. The influences of the Isthmus of Kra located in peninsular Thailand should be appreciated as an ancient zoogeographical barrier. We confirmed the sympatric distribution in the common tree shrew populations including the two independent species, Tupaia glis and Tupaia belangeri, in the south region of the Isthmus of Kra including original localities of $\mathrm{R}$ and $\mathrm{S}$ populations in the present study [5-7]. So, we can suggest that both $\mathrm{R}$ and $\mathrm{S}$ populations may contain the complicated genetic races influenced by the Isthmus of Kra. Indeed, the principal component charts did not separate $\mathrm{R}$ population from S population (Fig. 1). Although K population has been thought to belong simply to north group, we suggest that $\mathrm{R}$ and $\mathrm{S}$ population may contain individuals from both north and south groups separated by the ancient Kra barrier.

We noticed that the skull size of $\mathrm{T}$ population was not sta- tistically different from that of $\mathrm{S}$ population in many measurements in each sex (Tables 3 and 4). The skin color of this population has been thought to be similar to that of $\mathrm{Cal}$ losciurus caniceps concolor and Callosciurus caniceps fallax, the peninsular Thailand and related island populations in skin color character $[2,11]$. Since Terutau Island is located near the border between Thailand and Malaysia, we think that the north group of the Isthmus of Kra may not be genetically related to this population. We suggest that the island-isolation effects in Terutau Island had influences on the skull size and shape of the ancestors in south group of mainland. Geographical factors of the size similarity between $\mathrm{S}$ and $\mathrm{T}$ populations should be examined in the future.

The present data in the proportional analysis (Tables 5 and 6) indicated the adaptational strategy in field behavior of each population. The smaller LBC indicated that the interorbital space was narrower and that the binocular sense has been well-developed in $\mathrm{T}$ population. It suggests that the skull has been highly adapted to arboreal behavior. In contrast, the large LBO suggests that the animal was more adaptive for terrestrial life in K population. The large GNB 

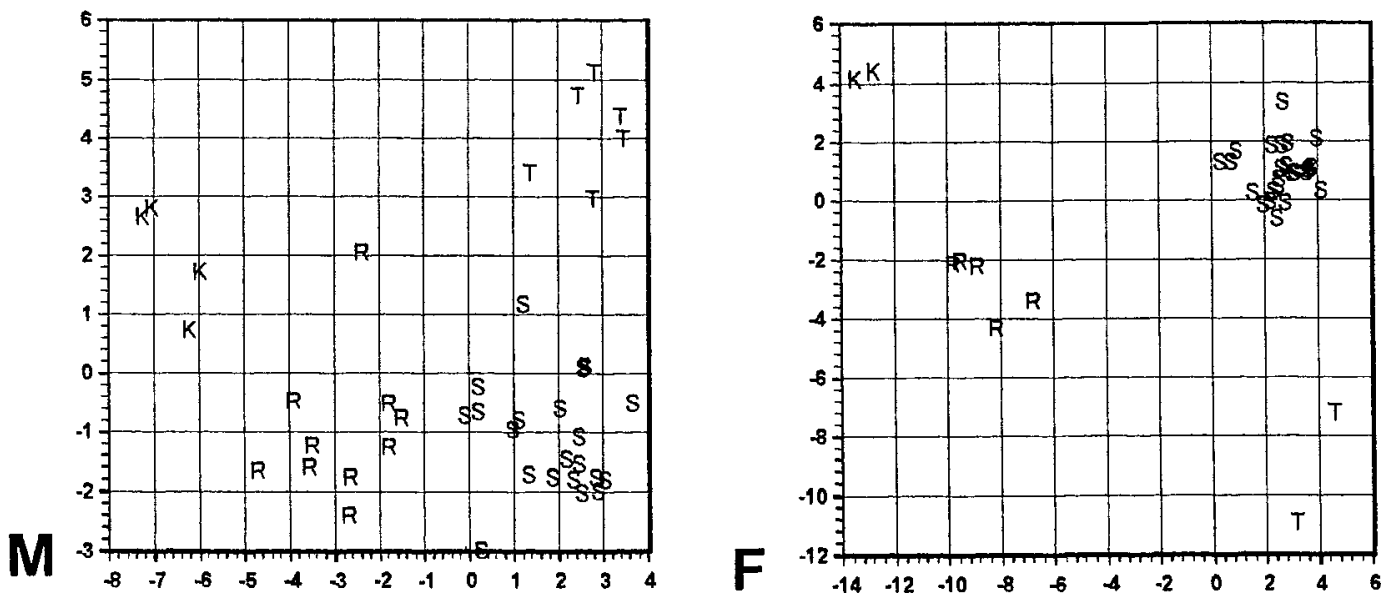

Fig. 2. The visualized results of the canonical discriminant analysis among 4 populations. Scattergrams showing the individual scores on the discriminant axes 1 (horizontal) and 2 (vertical). The locality symbols are explained in Table 1. M) Male. The first function comprises $66.4 \%$ of the variance and the second function $26.9 \%$. F) Female. The first function comprises $69.8 \%$ of the variance and the second function $20.3 \%$.

Table 7. Character loading factors observed from the principal component analysis

\begin{tabular}{|c|c|c|c|c|c|c|c|c|c|c|c|c|c|c|}
\hline & & PL & ML & CL & SL & MWN & LBO & LBC & GNB & GOB & MPL & DL & LMR1 & \\
\hline \multirow[t]{2}{*}{ Male } & PC1 & 0.979 & 0.980 & 0.933 & 0.954 & 0.750 & 0.709 & 0.765 & 0.534 & 0.876 & 0.936 & 0.928 & 0.666 & \\
\hline & PC2 & -0.043 & -0.056 & -0.243 & -0.045 & -0.024 & 0.233 & 0.569 & 0.751 & -0.004 & -0.129 & -0.034 & -0.030 & \\
\hline \multirow[t]{3}{*}{ Female } & PC1 & 0.960 & 0.967 & 0.948 & 0.942 & 0.724 & 0.928 & 0.730 & 0.754 & 0.914 & 0.930 & 0.949 & 0.650 & \\
\hline & PC2 & -0.117 & -0.102 & -0.170 & -0.154 & -0.398 & 0.078 & 0.400 & 0.160 & -0.060 & -0.114 & 0.014 & 0.633 & \\
\hline & & GPB & LBS & LBR & LBM & LBSR & HAB & LC & LMR2 & TM & HM & AHR & OHR & P.V.E \\
\hline \multirow[t]{2}{*}{ Male } & PC1 & 0.809 & 0.842 & 0.951 & 0.905 & 0.926 & 0.836 & 0.914 & 0.775 & 0.571 & 0.893 & 0.879 & 0.870 & 72.13 \\
\hline & PC2 & 0.256 & -0.315 & -0.095 & -0.046 & 0.027 & 0.295 & -0.115 & -0.039 & -0.292 & -0.113 & -0.168 & 0.033 & 5.97 \\
\hline \multirow[t]{2}{*}{ Female } & PC1 & 0.702 & 0.826 & 0.939 & 0.941 & 0.827 & 0.736 & 0.898 & 0.588 & 0.329 & 0.888 & 0.878 & 0.886 & 70.53 \\
\hline & PC2 & 0.417 & -0.212 & -0.107 & -0.033 & 0.223 & 0.127 & -0.039 & 0.674 & 0.359 & -0.262 & -0.254 & -0.261 & 8.03 \\
\hline
\end{tabular}

Percentages of the variation explained by each factor $(*)$.

and GOB indicated that the braincase has been enlarged bilaterally in this population, but the functional significance of the characters cannot be easily explained.

The positive loading factors and the explaining percentage of the first principal component scores suggest that the size factor contributes to the separation between the populations in this analysis (Table 7 and Fig. 1). The plots of $\mathrm{R}$ population could not be separated from those of $\mathrm{S}$ population in the principal component analysis, but the similarities were not so obvious that canonical discriminant analysis could distinguish these two populations (Figs. 1 and 2).

In this study, the sample size was smaller in female of $\mathrm{K}$ and $\mathrm{T}$ populations. The standard deviations were larger in female than in male at least in $\mathrm{K}$ and $\mathrm{T}$ populations. The number of skulls should be larger in the future. However, we can point out that the statistical tests and the multivariate analyses were valid also in female as well as in male in this examination.
ACKNOWLEDGEMENTS. We thank Dr. Richard W. Thorington, Jr., Dr. James Mead and Ms. Linda Gordon (Smithsonian Institution) for their help and encouragement in this study. This study was financially supported by Grant-in-Aids for Scientific Research nos. 13640705, 13575027, 14405030 and 15570092 from the Ministry of Education, Science and Culture, Japan.

\section{REFERENCES}

1. Bonhote, J. L. 1901. On a second collection of mammals made by Mr. Th. H. Lyle in Siam. Proc. Zool. Soc. Lond. 1901: 5256.

2. Boonsong, L. and McNeely, J. A. 1988. Mammals of Thailand, 2nd ed., Saha Karn Bhaet, Co., Bangkok.

3. Corbet, G. B. and Hill, J. E. 1992. The Mammals of the Indomalayan Region: A Systematic Review. Oxford Univ. Press, Oxford.

4. Driesch, A. 1976. A guide to the measurement of animal bones from archaeological sites. Cambridge, MA, Harvard Univ. 
Table 8. Coefficients in each discriminant function

\begin{tabular}{|c|c|c|c|c|c|c|c|c|c|c|c|c|c|c|c|}
\hline & & PL & ML & CL & SL & MWN & LBO & LBC & GNB & GOB & MPL & DL & LMR1 & & \\
\hline \multirow[t]{3}{*}{ male } & CAV1 & -0.777 & 1.564 & -1.731 & 0.579 & -0.410 & -0.048 & -1.322 & 0.464 & 0.919 & 1.107 & -1.312 & 0.093 & & \\
\hline & CAV2 & 0.792 & 0.024 & 2.030 & 0.165 & 0.455 & 0.205 & -0.279 & -0.850 & 0.285 & -2.203 & -0.201 & -0.442 & & \\
\hline & CAV3 & 0.780 & -0.640 & 0.165 & 0.598 & 1.018 & -0.307 & -0.199 & 0.543 & 0.422 & -1.071 & -0.209 & 1.139 & & \\
\hline \multirow[t]{4}{*}{ female } & CAV1 & -6.322 & 8.775 & -0.100 & -5.477 & 8.955 & 1.871 & -0.062 & 0.715 & -5.431 & -4.013 & -0.528 & -0.811 & & \\
\hline & CAV2 & -3.387 & 5.345 & -0.694 & -0.641 & 0.337 & -0.481 & -0.410 & 0.663 & 2.386 & 1.602 & 0.305 & -0.640 & & \\
\hline & CAV3 & 0.072 & 0.079 & 0.081 & 0.817 & -4.016 & -0.848 & -0.052 & 0.684 & -1.224 & -4.530 & 4.399 & -6.781 & & \\
\hline & & GPB & LBS & LBR & LBM & LBSR & HAB & LC & LMR2 & $\mathrm{TM}$ & HM & AHR & OHR & c. t. & e. v. \\
\hline \multirow[t]{3}{*}{ male } & CAV1 & -0.636 & 3.668 & -1.427 & 0.814 & -0.635 & -1.674 & -0.317 & -0.744 & -0.570 & -1.909 & -0.353 & 1.538 & 44.920 & 10.071 \\
\hline & CAV2 & 0.831 & -0.201 & -0.553 & -0.758 & -1.079 & -1.862 & 0.414 & -0.445 & -0.907 & -0.762 & 0.942 & 0.417 & 4.459 & 4.084 \\
\hline & CAV3 & -0.891 & -0.491 & 0.175 & -0.022 & 0.977 & -1.448 & 0.450 & -1.326 & 1.449 & 0.202 & -0.423 & -0.924 & 0.135 & 1.018 \\
\hline \multirow[t]{3}{*}{ female } & CAV1 & -9.240 & 1.441 & 0.792 & -2.645 & 1.250 & 1.008 & 3.039 & 3.946 & -3.549 & 1.389 & -1.101 & 1.713 & 73.642 & 31.225 \\
\hline & CAV2 & -2.668 & 0.935 & -2.998 & -0.821 & 0.846 & 0.170 & -2.384 & 4.203 & 9.357 & -0.101 & -1.856 & 3.665 & -46.237 & 9.090 \\
\hline & CAV2 & 2.675 & -2.225 & 1.848 & 0.006 & 2.267 & 1.229 & -0.718 & 0.768 & 0.606 & 1.672 & -0.729 & 0.498 & -17.417 & 4.421 \\
\hline
\end{tabular}

F-values are 2.297 in male, and 2.922 in female. c.t.: constant term. e.g.: eigen values.

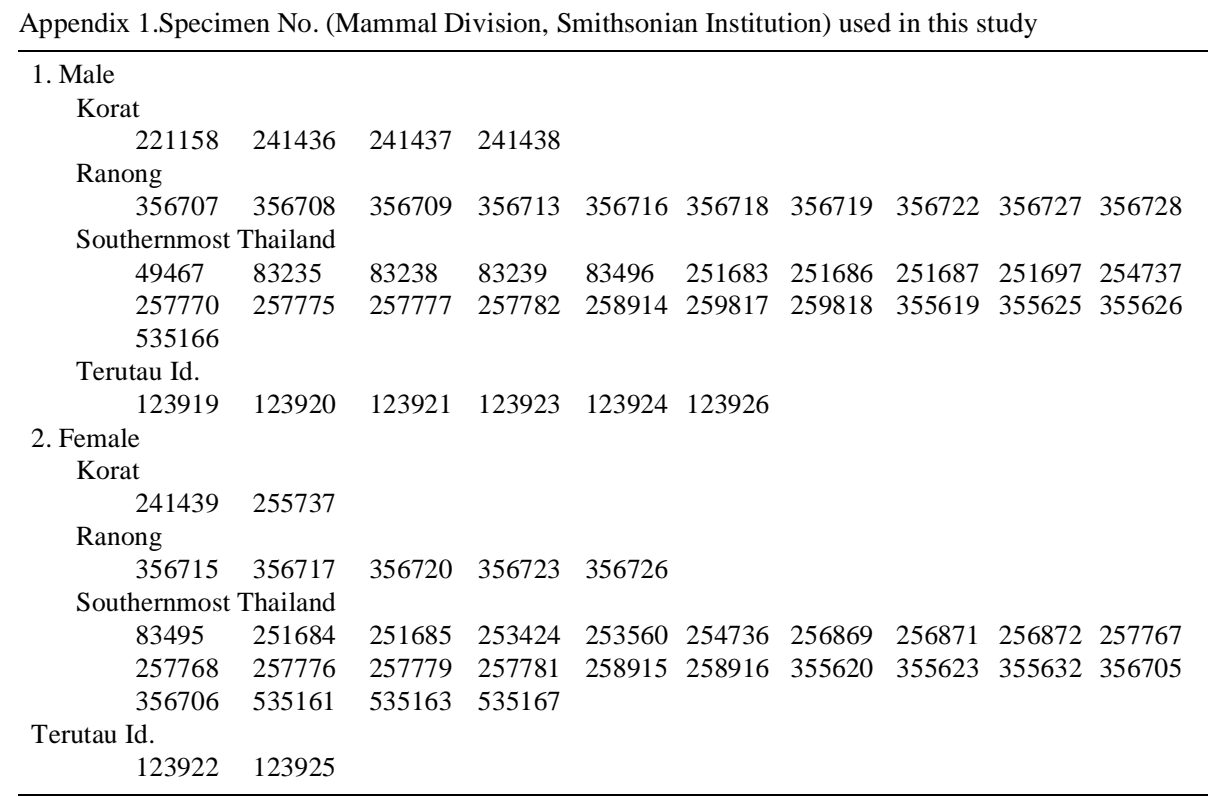

Press.

5. Endo, H., Hayashi, Y., Rerkamnuaychoke, W., Nadee, N., Nabhitabhata, J., Kawamoto, Y., Hirai, H., Kimura, J., Nishida, T. and Yamada, J. 2000. Sympatric distribution of the two morphological types of the common tree shrew in Hat-Yai Districts (South Thailand). J. Vet. Med. Sci. 62: 759-761.

6. Endo, H., Nishiumi, I., Hayashi, Y., Rashdi, A. B. M., Nadee, N., Nabhitabhata, J., Kawamoto, Y., Kimura, J., Nishida, T. and Yamada, J. 2000. Osteometrical analysis in skull of the common tree shrew from both sides of the Isthmus of Kra. $J$. Vet. Med. Sci. 62: 375-378.

7. Hirai, H., Hirai, Y., Kawamoto, Y., Endo, H., Kimura, J. and Rerkamnuaychoke, W. 2002. Cytogenetic differentiation of two sympatric tree shrew taxa found in the southern part of the Isthmus of Kra. Chromosome Research 10: 313-327.

8. Kloss, C. B. 1916. On a collection of mammals from the coast and islands of southeast Siam. Proc. Zool. Soc. Lond. 1916: 27-75

9. Medway, L. 1969. The Wild Mammals of Malaya. Oxford Univ. Press, Oxford.

10. Miller, G. S. 1903. A new squirrel from lower Siam. Proc. Biol. Soc. Wash. 16: 147-148.

11. Moore, J. C. and Tate, G. H. H. 1965. A study of the diurnal squirrels, Sciurinae, of the Indian Indochinese subregions. Fieldiana Zool. 48: 1-351.

12. Robinson, H. C. and Kloss, C. B. 1914. On new mammals, mainly from Boden and the adjacent islands, east coast of the Malay peninsula. Ann. Mag. Nat. Hist. 8: 223-234.

13. Wilson, D. E. and Reeder, D. A. 1993. Mammal Species of the World. A Taxonomic and Geographic Reference. 2nd ed. Smithsonian Institution Press, Washington. 